\title{
LIF and LIF-R expression in the endometrium of fertile and infertile women: A prospective observational case-control study
}

\author{
CHRYSOULA MARGIOULA-SIARKOU ${ }^{1,2^{*}}$, YANNIS PRAPAS ${ }^{1,2^{*}}$, STAMATIOS PETOUSIS $^{1,2^{*}}$, \\ STEFANOS MILIAS $^{3}$, KONSTANTINOS RAVANOS ${ }^{2}$, IOANNIS KALOGIANNIDIS ${ }^{1,2}$, \\ GEORGE MAVROMATIDIS ${ }^{1}$, CONSTANTINOS HAITOGLOU ${ }^{4}$, NIKOLAOS PRAPAS ${ }^{1,2}$ and DAVID ROUSSO ${ }^{1}$ \\ ${ }^{1} 3$ rd Department of Obstetrics and Gynaecology, Aristotle University of Thessaloniki, 56242 Thessaloniki; \\ ${ }^{2}$ IAKENTRO, Infertility Treatment Center, 54250 Thessaloniki; ${ }^{3}$ Department of Pathology, 424 General Army Hospital, \\ 57001 Thessaloniki; ${ }^{4}$ Laboratory of Biochemistry, Aristotle University of Thessaloniki, 56242 Thessaloniki, Greece
}

Received December 7, 2015; Accepted February 16, 2016

DOI: $10.3892 / \mathrm{mmr} .2016 .5142$

\begin{abstract}
The aim of the present study was to determine the expression of leukemia inhibitory factor (LIF) and LIF receptor (LIF-R) in the endometrium of fertile and infertile women during the implantation window. A prospective study was conducted between March 2013 and March 2015 at IAKENTRO, Infertility Treatment Center (Thessaloniki, Greece) and the 3rd Department of Obstetrics and Gynecology, Aristotle University of Thessaloniki (Thessaloniki, Greece). The patient group consisted of women diagnosed with infertility, whereas the control group consisted of women who had delivered at least one live newborn (fertile women). An endometrial biopsy was obtained using a Pipelle on day 7 or 8 post-ovulation, and the expression of LIF and LIF-R was assessed by immunohistochemistry in epithelial and stromal cells. Primary outcomes included positive cellular percentage, staining intensity and $\mathrm{H}$-score. $\mathrm{P}<0.05$ was considered to indicate a statistically significant difference. Overall, 45 women were included in the present analysis (15 fertile women and 30 infertile women). Mean age was $32.8 \pm 6.0$ years for the fertile group, and 37.6 \pm 3.7 for the infertile group. LIF and LIF-R expression was significantly reduced in the epithelial cells of infertile women ( $\mathrm{P}=0.05$ and $\mathrm{P}=0.006$, respectively). However, no significant differences were detected with regards to the expression of LIF in stromal cells $(\mathrm{P}=0.95)$. In addition, LIF-R expression was relatively higher in the stromal cells of the fertile group; however, the difference did not reach
\end{abstract}

Correspondence to: Dr Chrysoula Margioula-Siarkou, 3rd Department of Obstetrics and Gynaecology, Aristotle University of Thessaloniki, 49 Konstantinoupoleos Street, 56242 Thessaloniki, Greece

E-mail:m.s.chrysoula@mail.gr

${ }^{*}$ Contributed equally

Key words: endometrium, implantation, leukemia inhibitory factor infertility, leukemia inhibitory factor receptor statistical significance $(\mathrm{P}=0.10)$. In conclusion, endometrial expression of LIF and LIF-R is significantly reduced in the epithelial cells of infertile women. Expression patterns of LIF-R in stromal cells require further research in order to achieve definitive results.

\section{Introduction}

Implantation occurs during a specific period of the menstrual cycle, known as the window of implantation (between day 6 and day 10 of the cycle, following the luteinizing hormone surge), and is dependent on a synchronized dialogue between the embryo and endometrium. This dialogue is mediated by specific biochemical factors, including hormones, growth factors, enzymes, integrins and cytokines (1-3).

Leukemia inhibitory factor (LIF), which is a multifunctional protein that belongs to the interleukin- 6 cytokine family, exerts numerous regulatory actions on various domains of cellular function (4). LIF was initially reported to induce macrophage differentiation in M1 murine myeloid leukemic cells, and to suppress their proliferation in vitro (5). LIF was later examined in transgenic mice, and was identified as the first necessary cytokine for implantation $(6,7)$. Furthermore, LIF expression has been detected in both the embryo and endometrium, and its role expands from blastocyst development and endometrial differentiation to blastocyst attachment and invasion of the endometrium $(4,8)$.

LIF exerts its actions by interacting with its receptor, which is a heterodimer composed of two transmembrane proteins, LIF receptor (LIF-R) and glycoprotein 130 (gp130) (9-11). LIF-R selectively interacts with LIF, whereas gp130 may also interact with other cytokines. LIF is initially connected to LIF-R with low-affinity binding, which in turn induces dimerization with gp130, leading to a high-affinity receptor $(1,4,12,13)$. Development of the heterodimer receptor induces numerous intracellular signaling pathways, including the phosphatidylinositol-3-kinase, mitogen-activated protein kinase, and janus kinase/signal transducer and activator of transcription pathways, through which LIF performs its numerous actions (14-17).

The presence of LIF and LIF-R in endometrial cells, alongside alterations in their expression levels during the 
menstrual cycle, supports their decisive role in the normal implantation process $(18,19)$. During the proliferative phase, LIF and LIF-R endometrial expression is reduced; however, after ovulation there is a gradual increase in LIF and LIF-R levels, which continues until the end of the menstrual cycle. LIF expression is maximized in endometrial cells during the mid-luteral phase $(8,20,21)$. LIF concentration is maximized between days 7 and 12 post-ovulation, whereas the levels of LIF-R and gp130 have been reported to peak between days 19 and 25 of the menstrual cycle (22-24). The increased expression of LIF and its receptors during the mid-secretory phase coincides with the implantation window, thus indicating the significance of this cytokine for endometrial receptivity (25).

Despite the fact that a decisive role has been recognized for LIF in animal implantation, few studies have compared LIF expression patterns between fertile and infertile women. Furthermore, a review of the literature indicates that no data is available regarding the expression patterns of LIF-R in the epithelial and stromal cells of infertile women during the implantation window. Therefore, the main aim of the present study was to compare LIF and LIF-R endometrial expression between infertile and fertile women during the implantation window.

\section{Materials and methods}

Study design and subjects. The patients were recruited from 3rd Department of Obstetrics and Gynecology of Aristotle University of Thessaloniki and IAKENTRO Infertility Treatment Center (Thessaloniki, Greece). The present analysis is a prospective observational case-control study, which was performed between March 2013 and March 2015. The patient group consisted of infertile women, whereas the control group consisted of fertile women. Infertile women were defined as patients that had failed to achieve a clinical pregnancy after $\geq 12$ months of regular unprotected sexual intercourse. Fertile women were defined as subjects with at least one live newborn, who had not presented with signs or symptoms of infertility following their last childbirth. Exclusion criteria for both groups included: Age $>42$ years old, history of gynecological surgical procedures in the cervix and uterus, endometrial hyperplasia, polyps, gynecological cancer, and cervical intra-epithelial dysplasia. Fertile women with a history of miscarriage and ectopic pregnancies were also excluded. Informed consent was obtained from all of the women participating in the present study. The present study was approved by the Institutional Review Board and Ethical Committee of Aristotle University of Thessaloniki (Thessaloniki, Greece).

Description of intervention. All women underwent persistent ultrasound evaluation, in order to determine their day of ovulation. Transvaginal ultrasound was performed from the $8^{\text {th }}$ menstrual day on a daily basis, and the maximum diameter of the predominant follicle was measured. The day during which the maximum diameter of the follicle was detected, which on the next day was followed by elimination or heterogeneity of clear ultrasound limits was considered the ovulation day. The cycle was considered as ovulatory only if a follicle with a mean diameter $>18 \mathrm{~mm}$ was observed, otherwise the subject was excluded from the study.
All women fulfilling the inclusion criteria of the present study had an endometrial biopsy 7 or 8 days after ovulation. Endometrial biopsy was performed using a Pipelle de Cornier ${ }^{\circledR}$ (Prodimed, Neuilly-en-Thelle, France). All biopsies were performed by the same physician (Y.P). Endometrial tissue was added to $10 \%$ formalin solution and immunohistochemistry (IHC) was performed by a specialized pathologist. The pathologist was unaware of the sample origin (fertile/infertile) and the menstrual day of the biopsy (blind examiner).

$I H C$. Each specimen was fixed in $10 \%$ buffered formalin solution for $12 \mathrm{~h}$ at room temperature. The specimens were prepared according to the routine procedure: Overnight dehydration in an automated closed type tissue processor, followed by paraffin embedding. Serial $3.5 \mu \mathrm{m}$ sections were cut from each paraffin block using a rotary microtome, and were set in positively charged SuperFrost microscope slides. These slides were used for immunohistochemical staining, whereas another plain microscope slide was stained with hematoxylin and eosin (Atom Scientific, Manchester, UK). The positively charged slides were deparaffinized in an incubator at $64.5^{\circ} \mathrm{C}$ for $45 \mathrm{~min}$. Immunostaining was performed using an automated immunostainer (Bond; Leica Biosystems Ltd., Newcastle, UK). A kit was used with the immunostainer for the detection of primary antibodies (Bond Polymer Refine Detection; Leica Biosystems Ltd.), which contained 3.0\% hydrogen peroxide, polymer penetration enhancer (Post Primary), polymer-horseradish peroxidase anti mouse/rabbit immunoglobulin G, 3,3'-diaminobenzidine tetrahydrochloride and hematoxylin. The deparaffinization was performed with incubation of the slides for $1 \mathrm{~h}$ in $60^{\circ} \mathrm{C}$, prior to the procedure. Using the immunohistochemical kit provided the slides were incubated with $\mathrm{H}_{2} \mathrm{O}_{2}$ for $5 \mathrm{~min}$, followed by application of the optimal antibody for $10 \mathrm{~min}$ (LIF in pH9 and LIFR in pH6), incubated with the post primary antibody solution for $10 \mathrm{~min}$, with the polymer for $10 \mathrm{~min}$, with DAB for $10 \mathrm{~min}$ and stained with hematoxylin for $5 \mathrm{~min}$. At the end of the protocol, the slides were hydrated through ascending alcohols, cleared with xylene and mounted. Rabbit polyclonal antibodies were used for the detection of LIF (cat. no. HPA018844; Sigma-Aldrich, St. Louis, MO, USA) and LIF-R expression (cat. no. sc-659; C-19; Santa Cruz Biotechnology, Inc., Dallas, TX, USA, ).

Histological dating was assessed according to the histological criteria outlined by Noyes et al (26). A sample was considered as out-of-phase when the histological dating differed $>3$ days from the chronological dating. IHC staining was assessed by optical microscopy (DM1000; Leica Microsystems GmbH, Weltzar, Switzerland). Liver, kidney and lung tissues were used as control samples. Endometrial samples were considered positive when the cells were stained brown. The percentage of positive cell staining was measured in every sample. Staining intensity was evaluated using a score scale between 0 and 3: Score 0, no staining; 1, mild staining; 2, moderate staining; and 3, intense staining. H-score was defined as $\Sigma x i(i+1)$ of positive cell percentage and staining intensity (27). The H-score is a method of assessing the extent of nuclear immunoreactivity. The score is obtained by the formula: $3 \mathrm{x}$ percentage of strongly staining nuclei $+\mathrm{x}$ percentage of moderately staining nuclei + percentage of weakly staining nuclei, giving a range of 0 to 300 . These parameters were 
examined separately for epithelial and stromal cells. Scoring of all tissues was performed blindly by the same physician (S.M.).

Independent variables and epidemiological characteristics. The epidemiological characteristics of the women included in the present study were examined. Obstetrical history of the women was examined, including gravidity, parity, mode of delivery for fertile women, and number of potential miscarriages and abortions. For the infertile women, the exact cause of infertility, and previous attempts at in vitro fertilization and their outcome were examined. Menstrual day on which the biopsy was performed, the interval between day of ovulation and day of biopsy, and endometrial thickness at biopsy were also recorded.

Primary and secondary outcomes. Primary outcomes were defined as the percentage of positive cellular staining, the intensity of staining, and the H-score of LIF and LIF-R expression in the epithelial and stromal cells of fertile and infertile women. Secondary outcomes included the endometrial dating of obtained samples, as well as the rate of out-of-phase endometrial tissues in the two study groups.

Statistical analysis. Statistical analysis was performed using SPSS 18.0 (SPSS, Inc., Chicago, IL, USA). Mean values, standard deviation and standard error of the mean were estimated for continuous variables, whereas categorical variables were expressed as percentages. Numerical variables of the present study were tested for normality using the Kolmogorov-Smirnov test. Independent samples t-test was used for the comparison of normally distributed variables, and Mann-Whitney test was used for the comparison of non-normally distributed variables. Fisher's exact test $\left(\chi^{2}\right.$ criterion) was used to analyze the categorical parameters of this study. Both primary and secondary outcomes were compared between the fertile and infertile women (groups 1 and 2). $\mathrm{P}<0.05$ was considered to indicate a statistically significant difference.

\section{Results}

Patient characteristics. Overall, 20 fertile and 40 infertile women were initially included in the present study. Ovulation was confirmed in 17 fertile and 33 infertile women. Adequate tissue was obtained from 15 fertile and 30 infertile women. A flowchart of the patients included in the present study is presented in Fig. 1.

Mean age was $32.8 \pm 6.0$ years for fertile women, and $37.6 \pm 3.7$ years for infertile women. The parameters of gynecological history were similar between the two groups, and epidemiological characteristics for both groups are presented in Table I.

Endometrial biopsy characteristics. Menstrual day of ovulation was $12.3 \pm 1.4$ for fertile women, and $14.1 \pm 1.8$ for infertile women $(\mathrm{P}=0.002)$. The interval between ovulation and biopsy was comparable between the two groups $(\mathrm{P}=0.17)$. Menstrual day at biopsy obtainment was $19.3 \pm 1.6$ for the fertile group, and $21.3 \pm 1.8$ for the infertile group $(\mathrm{P}=0.001)$.

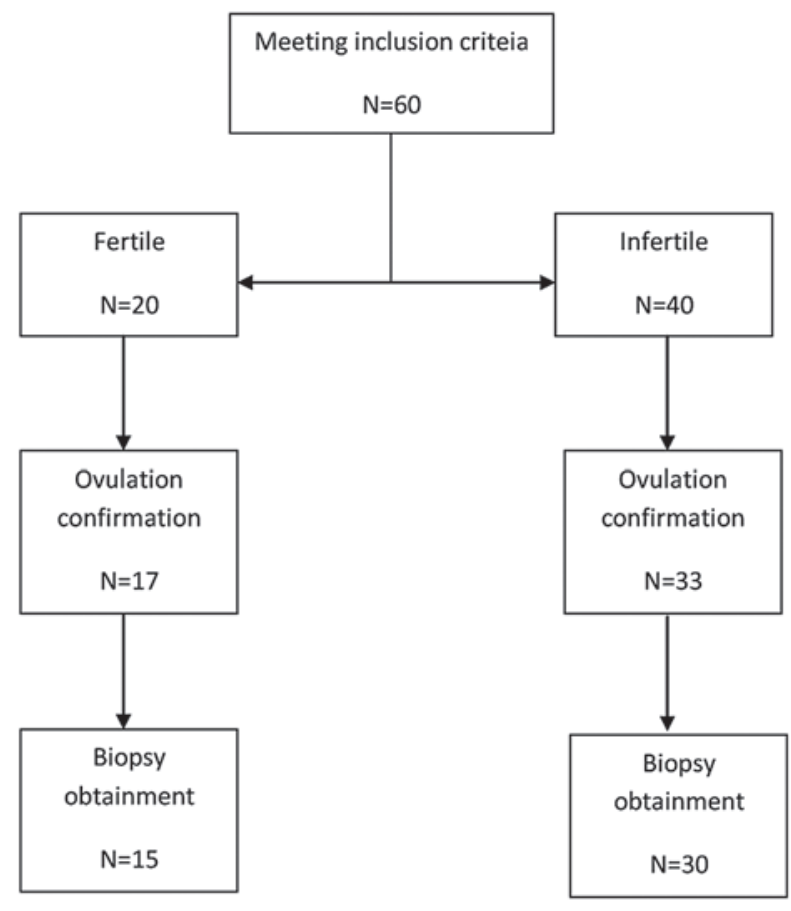

Figure 1. Flowchart of patients included in the present analysis.

Endometrial thickness was significantly lower in infertile women $(8.8 \pm 1.7 \mathrm{~mm})$ compared with in the fertile controls $(10.6 \pm 2.9 \mathrm{~mm})(\mathrm{P}=0.02)$. Characteristics of the endometrial biopsy are presented in Table II.

Primary outcomes. The expression of LIF and LIF-R was significantly lower in the epithelial cells of infertile women compared with the fertile controls. No significant differences were detected regarding the expression of LIF and LIF-R in the stromal cells between the two groups.

LIF expression was detected in a significantly higher percentage of epithelial cells in the fertile group compared with the infertile group $(\mathrm{P}=0.05)$. Intensity of staining was comparable between the two groups $(\mathrm{P}=0.21)$; however, $\mathrm{H}$-score for epithelial LIF expression was 105.7 28.5 in fertile women, as compared with $61.2 \pm 15.0$ in infertile women $(\mathrm{P}=0.05)$. Regarding LIF expression in stromal cells, no significant difference was detected between the fertile and infertile women $(\mathrm{P}=0.95)$.

The percentage of cells positively stained for LIF-R and staining intensity were significantly lower in the epithelial cells of infertile women $(\mathrm{P}=0.04$ and $\mathrm{P}=0.002$, respectively). In addition, LIF-R H-score for epithelial cells was significantly reduced in infertile women $(128.4 \pm 11.2)$ compared with fertile controls $(189.2 \pm 19.5)(\mathrm{P}=0.006)$. Regarding LIF-R expression in stromal cells, the $\mathrm{H}$-score was higher in fertile women; however, the difference did not reach statistical significance $(\mathrm{P}=0.10)$. Positive cellular percentage and staining intensity were comparable between the two groups $(\mathrm{P}=0.19$ and $\mathrm{P}=0.29$, respectively). Primary outcomes of the study are presented in Table III.

Images of IHC staining of LIF and LIF-R expression in the epithelial and stromal cells of fertile and infertile women are presented in Figs. 2-5. 
Table I. Epidemiological characteristics of the women included in the present analysis.

\begin{tabular}{|c|c|c|c|}
\hline Parameters & $\begin{array}{l}\text { Fertile group } \\
\quad(n=15)\end{array}$ & $\begin{array}{l}\text { Infertile group } \\
\qquad(\mathrm{n}=30)\end{array}$ & P-value \\
\hline \multicolumn{4}{|l|}{ Personal characteristics } \\
\hline Age $(\text { years })^{\mathrm{a}}$ & $32.8 \pm 6.0$ & $37.6 \pm 3.7$ & 0.02 \\
\hline Height $(\mathrm{m})^{\mathrm{a}}$ & $1.68 \pm 0.1$ & $1.63 \pm 0.07$ & 0.04 \\
\hline Weight $(\mathrm{kg})^{\mathrm{a}}$ & $69.3 \pm 3.6$ & $65.5 \pm 8.0$ & 0.32 \\
\hline \multicolumn{4}{|l|}{ Gynecological history } \\
\hline Menarche (years) ${ }^{\mathrm{a}}$ & $12.8 \pm 0.8$ & $12.9 \pm 1.8$ & 0.87 \\
\hline Menstrual cycle (days) ${ }^{\mathrm{a}}$ & $28.6 \pm 2.7$ & $27.7 \pm 1.5$ & 0.28 \\
\hline Menstruation (days) ${ }^{\mathrm{a}}$ & $4.0 \pm 0.8$ & $4.6 \pm 1.0$ & 0.14 \\
\hline \multicolumn{4}{|l|}{ Obstetrical history } \\
\hline Gravidity $^{\mathrm{b}}$ & $2.6(1-5)$ & $0.6(0-3)$ & $<0.001$ \\
\hline Parity $^{\mathrm{b}}$ & $1.8(1-3)$ & - & - \\
\hline Miscarriage $^{b}$ & - & $0.6(0-3)$ & - \\
\hline Abortion $^{\mathrm{b}}$ & $0.9(0-3)$ & - & - \\
\hline \multicolumn{4}{|l|}{ Cause of infertility } \\
\hline Poor ovarian response $\mathrm{c}^{\mathrm{c}}$ & - & $16(53.3)$ & - \\
\hline Tubal factor ${ }^{\mathrm{c}}$ & - & $7(23.3)$ & - \\
\hline Unexplained infertility ${ }^{c}$ & - & $7(23.3)$ & - \\
\hline \multicolumn{4}{|l|}{ Infertility history } \\
\hline Interval from infertility diagnosis (years) ${ }^{\mathrm{b}}$ & - & $4.7(1-14)$ & - \\
\hline Previous ART efforts ${ }^{\mathrm{b}}$ & - & $2.7(0-16)$ & - \\
\hline Previous IUI efforts ${ }^{\mathrm{b}}$ & - & $0.6(0-4)$ & - \\
\hline Previous IVF efforts ${ }^{\mathrm{b}}$ & - & $1.8(0-15)$ & - \\
\hline Previous Natural Cycle IVF ${ }^{\mathrm{b}}$ & - & $0.4(0-6)$ & - \\
\hline
\end{tabular}

Data are presented as the ${ }^{a}$ mean \pm standard deviation, ${ }^{b}$ mean (range), ${ }^{c} \mathrm{n}(\%)$. ART, assisted reproductive technology; IUI, intrauterine insemination; IVF, in vitro fertilization.

Secondary outcomes. The difference between normal histological dating according to menstrual day, and observed endometrial histological dating was significantly higher in the infertile group $(\mathrm{P}=0.02)$. In addition, there was a higher rate of out-of-phase endometrial tissues in the infertile group (66.7\%) compared with in the fertile control group (26.7\%) $(\mathrm{P}=0.01)$. Secondary outcomes of the present study are presented in Table IV.

\section{Discussion}

The present study demonstrated that LIF and LIF-R expression is significantly lower in the epithelial endometrial cells of infertile women, as compared with in fertile women. Furthermore, LIF-R expression may be impaired in the stromal cells of infertile women; however, this hypothesis requires further investigation in a larger sample size.

A review of the literature revealed a discrepancy regarding the expression of LIF in the epithelial endometrial cells of infertile women. Numerous studies have detected lower levels of this cytokine in the epithelial cells of infertile women compared with fertile women. Mariee et al (28) analyzed 15 endometrial biopsies from fertile women, and 45 from infertile women with unexplained infertility and multiple implantation failure (MIF), and reported that LIF expression was significantly decreased in the epithelium of infertile women. Similar observations were made by $\mathrm{Wu}$ et al (29) in a total of 30 endometrial biopsies, and by Dimitriadis et al (30) in a total of 15 biopsies from women with unexplained infertility and endometriosis, respectively. Decreased LIF expression has also been reported in studies using quantitative polymerase chain reaction or enzyme-linked immunosorbent assay analyses of either endometrial tissue or uterine flushing samples $(31,32)$.

Conversely, previous studies have reported similar LIF expression between the epithelial cells of fertile and infertile women. Xu et al (33) studied LIFexpression in 30 infertile women who suffered from recurrent pregnancy loss, and observed no significant difference in epithelial endometrial cell expression compared with the fertile control group. However, recurrent pregnancy loss alone should not be considered proof of infertility, since embryo attachment, invasion and implantation have successfully occurred in these cases. Furthermore, miscarriage that occurs after the $6^{\text {th }}$ week of gestation is usually caused by factors not related to the endometrium. Similar LIF expression between epithelial and stromal cells has also been observed by Mikolajczyk et al (34) in a study that compared the results from 14 infertile women with endometriosis and 21 fertile controls. 
Table II. Endometrial tissue characteristics.

\begin{tabular}{lccc}
\hline Parameters & $\begin{array}{c}\text { Fertile group } \\
(\mathrm{n}=15)\end{array}$ & $\begin{array}{c}\text { Infertile group } \\
(\mathrm{n}=30)\end{array}$ & $14.1 \pm 1.8$ \\
\hline Day of ovulation & $12.3 \pm 1.4$ & $21.3 \pm 1.8$ & 0.002 \\
Menstrual day at biopsy & $19.3 \pm 1.6$ & $7.2 \pm 0.4$ & 0.001 \\
Ovulation-to-biopsy interval & $7.0 \pm 0.4$ & $8.8 \pm 1.7$ & 0.17 \\
Endometrial thickness at biopsy & $10.6 \pm 2.9$ & 0.02 \\
\hline
\end{tabular}

Data are presented as the mean \pm standard deviation.

Table III. Primary outcomes of the present study.

\begin{tabular}{|c|c|c|c|}
\hline Parameters & $\begin{array}{l}\text { Fertile group } \\
\quad(n=15)\end{array}$ & $\begin{array}{l}\text { Infertile group } \\
\qquad(\mathrm{n}=30)\end{array}$ & P-value \\
\hline \multicolumn{4}{|l|}{ LIF } \\
\hline \multicolumn{4}{|l|}{ Epithelial cells } \\
\hline Positive nuclei percentage & $42.9 \pm 9.9$ & $24.9 \pm 5.5$ & $0.05^{\mathrm{a}}$ \\
\hline Intensity of staining & $2.3 \pm 0.2$ & $1.9 \pm 0.2$ & $0.21^{\mathrm{a}}$ \\
\hline H-score & $105.7 \pm 28.5$ & $61.2 \pm 15.0$ & $0.05^{\mathrm{a}}$ \\
\hline \multicolumn{4}{|l|}{ Stromal cells } \\
\hline Positive nuclei percentage & $64.6 \pm 5.9$ & $63.6 \pm 3.9$ & 0.89 \\
\hline Intensity of staining & $2.5 \pm 0.2$ & $2.6 \pm 0.1$ & $0.52^{\mathrm{a}}$ \\
\hline H-score & $155.0 \pm 18.5$ & $153.4 \pm 13.6$ & 0.95 \\
\hline \multicolumn{4}{|l|}{ LIF receptor } \\
\hline \multicolumn{4}{|l|}{ Epithelial cells } \\
\hline Positive nuclei percentage & $76.3 \pm 5.5$ & $63.0 \pm 4.3$ & $0.04^{\mathrm{a}}$ \\
\hline Intensity of staining & $2.5 \pm 0.1$ & $1.9 \pm 0.9$ & $0.002^{\mathrm{a}}$ \\
\hline H-score & $189.2 \pm 19.5$ & $128.4 \pm 11.2$ & 0.006 \\
\hline \multicolumn{4}{|l|}{ Stromal cells } \\
\hline Positive nuclei percentage & $75.0 \pm 3.1$ & $67.6 \pm 3.6$ & $0.19^{\mathrm{a}}$ \\
\hline Intensity of staining & $2.6 \pm 0.1$ & $2.4 \pm 0.1$ & $0.29^{\mathrm{a}}$ \\
\hline H-score & $198.3 \pm 11.9$ & $162.8 \pm 13.6$ & 0.10 \\
\hline
\end{tabular}

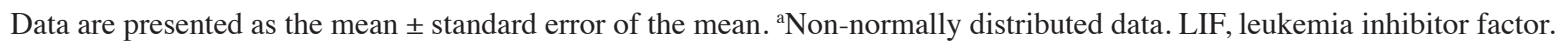

Table IV. Secondary outcomes of the study.

\begin{tabular}{lccc}
\hline Parameters & $\begin{array}{c}\text { Fertile group } \\
(\mathrm{n}=15)\end{array}$ & $\begin{array}{c}\text { Infertile group } \\
(\mathrm{n}=30)\end{array}$ & $16.9 \pm 0.7$ \\
\hline Endometrial dating $^{\mathrm{a}}$ & $16.6 \pm 0.7$ & $-5.3 \pm 0.7$ & 0.83 \\
Biopsy day-dating difference $^{\mathrm{b}}$ & $-2.3 \pm 0.9$ & $20(66.7)$ & 0.02 \\
Out-of-phase tissues $^{\mathrm{c}}$ & $4(26.7)$ & $8.8 \pm 1.7$ & 0.01 \\
Endometrial thickness at biopsy $^{\mathrm{a}}$ & $10.6 \pm 2.9$ & 0.02 \\
\hline
\end{tabular}

Data are presented as the ${ }^{\mathrm{a}}$ mean \pm standard deviation, ${ }^{\mathrm{b}}$ mean \pm standard deviation, ${ }^{\mathrm{c}} \mathrm{n}(\%)$.

However, uterine flushing, and not endometrial biopsy, was used in this previous study, thus providing a potential explanation for the different results obtained. Endometrial flushing may only contain exfoliated epithelial cells, whereas an endometrial biopsy contains both epithelial and stromal cells obtained in their functional condition. 


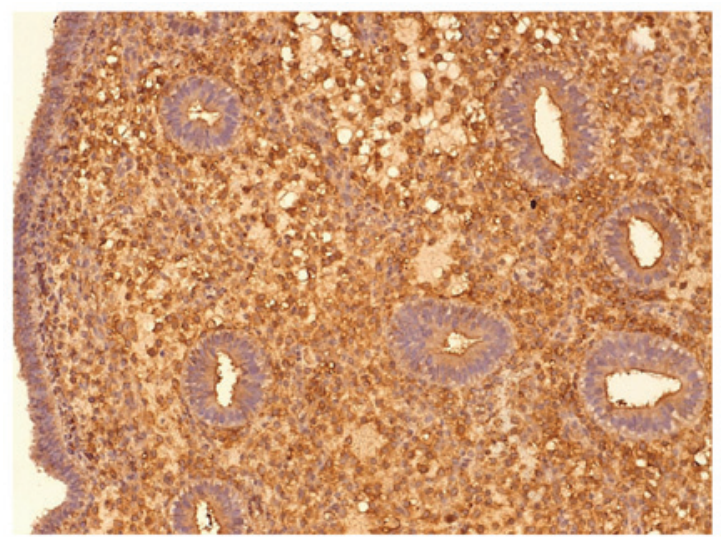

Figure 2. Leukemia inhibitory factor expression in endometrial cells of the fertile control group. Magnification, x200.

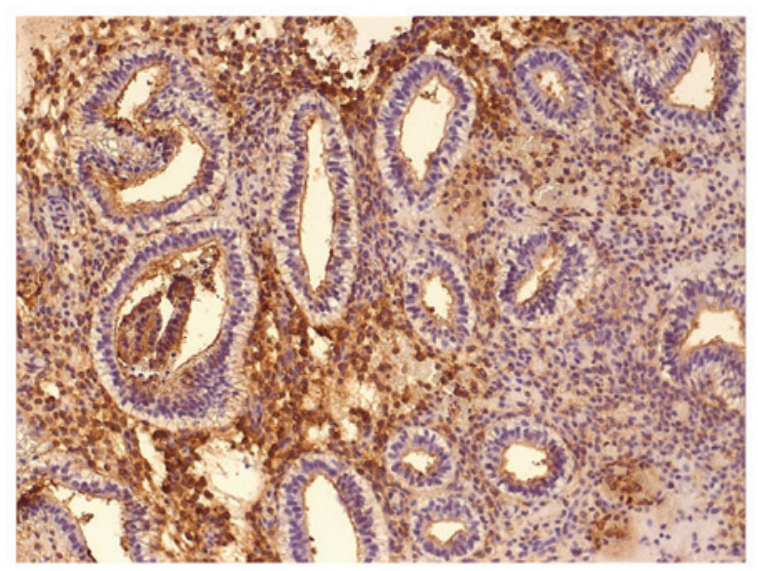

Figure 3. Leukemia inhibitory factor expression in endometrial cells of the infertile group. Magnification, x200.

The LIF intracellular signaling pathway is disturbed in not all, but in some cases of female infertility, dependent on the cause of infertility. Aghajanova et al (35) reached the conclusion that LIF intracellular signaling is predominantly affected in cases of unexplained infertility with MIF. In a subsequent study, the same author observed that deficient LIF expression is not a constant finding in infertile women; however, increased expression is indicative of endometrial receptivity (36). Therefore, it was concluded that evaluation of LIF expression on its own may not be sufficient for definitive conclusions regarding implantation achievement, even in women with unexplained infertility. Further research is required to assess the exact LIF expression patterns in various infertility sub-groups.

Numerous studies regarding LIF expression in the endometrium of infertile women have been performed; however, less studies have been conducted regarding the expression patterns of LIF-R. As previously stated, the basic condition of LIF action is its connection with LIF-R as a primary step to create a high-affinity binding heterodimer. However, a review of the literature revealed no study that directly compared LIF-R expression between fertile and infertile women during the implantation window. Cullinan et al (18) studied the expression patterns of LIF-R in the proliferative and secretory

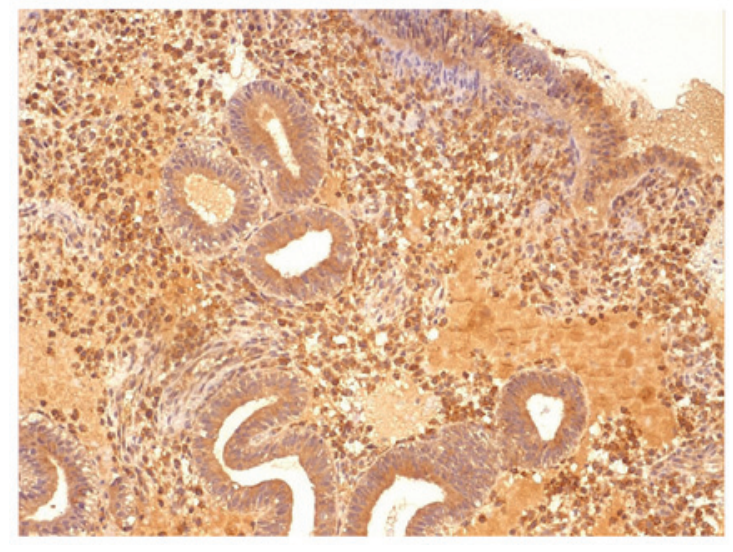

Figure 4. Leukemia inhibitory factor receptor expression in endometrial cells of the fertile control group. Magnification, x200.

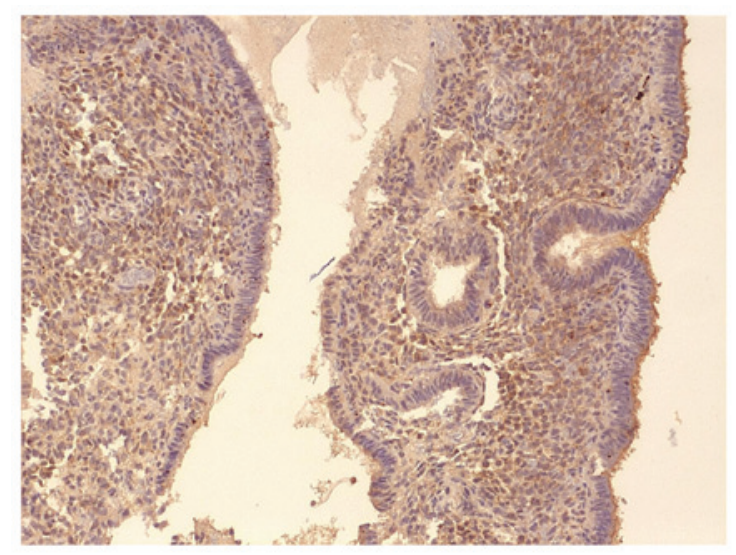

Figure 5. Leukemia inhibitory factor receptor expression in endometrial cells of the infertile group. Magnification, x200.

phases, concluding that there is a possible autocrine/paracrine interaction between LIF and LIF-R at the luminal epithelium. In addition, in a hamster study performed by Ding et al (37) a significant role for LIF-R was identified in uterine receptivity and implantation. The present study is one amongst few that has observed significantly decreased levels of LIF-R in the epithelial cells of infertile women, alongside reduced LIF levels $(38,39)$. Furthermore, as the decreased expression levels of LIF-R in stromal cells in infertile women was significant; therefore, future research should be performed to clarify LIF-R expression patterns in stromal cells. These results suggested that the key factor for implantation is not LIF expression, but the synchronized expression of adequate LIF-R, in order to achieve normal implantation.

The present study is not devoid of limitations. A potential confounding variable may be the heterogeneity of the infertile patients with regards to the cause of infertility. However, the authors of the present study believe that expression patterns of various cytokines and molecules associated with the implantation process should be initially studied in the general infertile population, followed by in the specific sub-groups of infertility, particularly in those with unexplained infertility. The present analysis reported the results of a prospective study, including a large sample size, in the domain of reproductive immunology. 
Furthermore, the present study may be the first to report on the significant alteration of LIF-R levels in the endometrium of infertile women. Expansion of the study into a larger number of patients, and evaluation of LIF and LIF-R expression in the various sub-groups of infertility will hopefully lead to safer and more reliable conclusions regarding the potential pathogenetic role of these molecules in infertility.

In conclusion, the present analysis demonstrated that LIF and LIF-R expression was decreased in the epithelial cells of infertile women. This observation further underlines the predominant role of LIF-R in endometrial receptivity. Further studies elucidating the expression patterns of cytokines in various sub-groups of infertility may define their exact etiopathogenetic role in endometrial receptivity. Investigation into the expression patterns of LIF and LIF-R may ideally lead to the development of tests that could assess endometrial receptivity, in order to improve implantation rates in assisted reproductive technology.

\section{Acknowledgements}

The present study was supported by the IKY Fellowships of Excellence for Postgraduate Studies in Greece - Siemens Program.

\section{References}

1. Dimitriadis E, Menkhorst E, Salamonsen LA and Paiva P: Review: LIF and IL11 in trophoblast-endometrial interactions during the establishment of pregnancy. Placenta 31 (Suppl): S99-S104, 2010.

2. Koot YE and Macklon NS: Embryo implantation: Biology, evaluation, and enhancement. Curr Opin Obstet Gynecol 25: 274-279, 2013.

3. Tabibzadeh S and Babaknia A: The signals and molecular pathways involved in implantation, a symbiotic interaction between blastocyst and endometrium involving adhesion and tissue invasion. Hum Reprod 10: 1579-1602, 1995.

4. Paiva P, Menkhorst E, Salamonsen L and Dimitriadis E: Leukemia inhibitory factor and interleukin-11: Critical regulators in the establishment of pregnancy. Cytokine Growth Factor Rev 20: 319-328, 2009.

5. Gearing DP, Gough NM, King JA, Hilton DJ, Nicola NA, Simpson RJ, Nice EC, Kelso A and Metcalf D: Molecular cloning and expression of cDNA encoding a murine myeloid leukaemia inhibitory factor (LIF). EMBO J 6: 3995-4002, 1987.

6. Stewart CL, Kaspar P, Brunet LJ, Bhatt H, Gadi I, Köntgen F and Abbondanzo SJ: Blastocyst implantation depends on maternal expression of leukaemia inhibitory factor. Nature 359: 76-79, 1992.

7. Stewart CL: The role of leukemia inhibitory factor (LIF) and other cytokines in regulating implantation in mammals. Ann NY Acad Sci 734: 157-165, 1994.

8. Aghajanova L: Leukemia inhibitory factor and embryo human implantation. Ann NY Acad Sci 1034: 176-183, 2004.

9. Singh M, Chaudry P and Asselin E: Bridging endometrial receptivity and implantation: Network of hormones, cytokines, and growth factors. J Endocrinol 210: 5-14, 2011.

10. Sánchez-Cuenca J, Martín JC, Pellicer A and Simón C: Cytokine pleiotropy and redundancy - gp130 cytokines in human implantation. Immunol Today 20: 57-59, 1999.

11. Classen-Linke I, Müller-Newen G, Heinrich PC, Beier HM and von Rango U: The cytokine receptor gp130 and its soluble form are under hormonal control in human endometrium and decidua. Mol Hum Reprod 10: 495-504, 2004.

12. Gearing DP, Thut CJ, VandeBos T, Gimpel SD, Delaney PB, King J, Price V, Cosman D and Beckmann MP: Leukemia inhibitory factor receptor is structurally related to the IL-6 signal transducer, gp130. EMBO J 10: 2839-2848, 1991.
13. Gearing DP, Comeau MR, Friend DJ, Gimpel SD, Thut CJ, McGourty J, Brasher KK, King JA, Gillis S, Mosley B, et al: The IL-6 signal transducer, gp130: An oncostatin $\mathrm{M}$ receptor and affinity converter for the LIF receptor. Science 255: 1434-1437, 1992.

14. Auernhammer CJ and Melmed S: Leukemia-inhibitory factor neuroimmune modulator of endocrine function. Endocr Rev 21: 313-345, 2000

15. Heinrich PC, Behrmann I, Müller-Newen G, Schaper F and Graeve L: Interleukin-6-type cytokine signalling through the gp130/Jak/STAT pathway. Biochem J 334: 297-314, 1998.

16. Duval D, Reinhardt B, Kedinger C and Boeuf H: Role of suppressors of cytokine signaling (Socs) in leukemia inhibitory factor (LIF) -dependent embryonic stem cell survival. FASEB J 14: 1577-1584, 2000.

17. Cheng JG, Chen JR, Hernandez L, Alvord WG and Stewart CL: Dual control of LIF expression and LIF receptor function regulate Stat 3 activation at the onset of uterine receptivity and embryo implantation. Proc Natl Acad Sci USA 98: 8680-8685, 2001 .

18. Cullinan EB, Abbondanzo SJ, Anderson PS, Pollard JW, Lessey BA and Stewart CL: Leukemia inhibitory factor (LIF) and LIF receptor expression in human endometrium suggests a potential autocrine/paracrine function in regulating embryo implantation. Proc Natl Acad Sci USA 93: 3115-3120, 1996.

19. Vogiagis D, Marsh MM, Fry RC and Salamonsen LA: Leukaemia inhibitory factor in human endometrium throughout the menstrual cycle. J Endocrinol 148: 95-102, 1996.

20. Tawfeek MA, Eid MA,Hasan AM, Mostafa M and El-Serogy HA: Assessment of leukemia inhibitory factor and glycoprotein 130 expression in endometrium and uterine flushing: A possible diagnostic tool for impaired fertility. BMC Womens Health 12: $10,2012$.

21. Sharkey AM, King A, Clark DE, Burrows TD, Jokhi PP, Charnock-Jones DS, Loke YW and Smith SK: Localization of leukemia inhibitory factor and its receptor in human placenta throughout pregnancy. Biol Reprod 60: 355-364, 1999.

22. Laird SM, Tuckerman EM, Dalton CF, Dunphy BC, Li TC and Zhang $\mathrm{X}$ : The production of leukaemia inhibitory factor by human endometrium: Presence in uterine flushings and production by cells in culture. Hum Reprod 12: 569-574, 1997.

23. Aghajanova L, Stavreus-Evers A, Nikas Y, Hovatta O and Landgren BM: Coexpression of pinopodes and leukemia inhibitory factor, as well as its receptor, in human endometrium. Fertil Steril 79 (Suppl 1): S808-S814, 2003.

24. Lass A, Weiser W, Munafo A and Loumaye E: Leukemia inhibitory factor in human reproduction. Fertil Steril 76: 1091-1096, 2001

25. Lei T, Yang ZQ, Xia T, Gan L, Chen XD, Yuan JH and Zhu Y: Stage-specific expression of leukaemia inhibitory factor and its receptor in rabbit pre-implantation embryo and uterine epithelium during early pregnancy. Reprod Domest Anim 39: 13-18, 2004.

26. Noyes RW, Hertig AI and Rock J: Dating the endometrial biopsy. Am J Obstet Gynecol 122: 262-263, 1975.

27. Ellis YO, Pider SE and Lee A: Tumors of the breast. 2nd Edition. In: Diagnostic Histopathology of Tumors. Fletcher C (ed.). Churchill Livingstone Elsevier, London, UK, pp1057-1070, 2007.

28. Mariee N, Li TC and Laird SM: Expression of leukaemia inhibitory factor and interleukin 15 in endometrium of women with recurrent implantation failure after IVF; correlation with the number of endometrial natural killer cells. Hum Reprod 27: 1946-1954, 2012.

29. Wu M, Yin Y, Zhao M, Hu L and Chen Q: The low expression of leukemia inhibitory factor in endometrium: Possible relevant to unexplained infertility with multiple implantation failures. Cytokine 62: 334-339, 2013.

30. Dimitriadis E, Stoikos C, Stafford-Bell M, Clark I, Paiva P, Kovacs $\mathrm{G}$ and Salamonsen LA: Interleukin-11 receptoralpha and leukemia inhibitory factor are dysregulated in endometrium of infertile women with endometriosis during the implantation window. J Reprod Immunol 69: 53-64, 2006.

31. Alizadeh Z, Shokrzadeh N, Saidijam M and Sanoee MF: Semi-quantitative analysis of HOXA11, leukemia inhibitory factor and basic transcriptional element binding protein $1 \mathrm{mRNA}$ expression in the mid-secretory endometrium of patients with endometriosis. Iran Biomed J 15: 66-72, 2011.

32. Hambartsoumian E: Endometrial leukemia inhibitory factor (LIF) as a possible cause of unexplained infertility and multiple failures of implantation. Am J Reprod Immunol 39: 137-143, 1998. 
33. Xu B, Sun X, Li L, Wu L, Zhang A and Feng Y: Pinopodes, leukemia inhibitory factor, integrin- $\beta 3$ and mucin- 1 expression in the peri-implantation endometrium of women with unexplained recurrent pregnancy loss. Fertil Steril 98: 389-395, 2012.

34. Mikolajczyk M, Wirstlein P and Skrzypczak J: Leukaemia inhibitory factor and interleukin 11 levels in uterine flushings of infertile patients with endometriosis. Hum Reprod 21: 3054-3058, 2006.

35. Aghajanova L, Altmäe S, Bjuresten K, Hovatta O, Landgren BM and Stavreus-Evers A: Disturbances in the LIF pathway in the endometrium among women with unexplained infertility. Fertil Steril 91: 2602-2610, 2009.

36. Aghajanova L: Update on the role of leukemia inhibitory factor in assisted reproduction. Curr Opin Obstet Gynecol 22:213-219, 2010 .
37. Ding T, Song H, Wang X, Khatua A and Paria BC: Leukemia inhibitory factor ligand-receptor signaling is important for uterine receptivity and implantation in golden hamsters (Mesocricetus auratus). Reproduction 135: 41-53, 2008.

38. Subramani E, Madogwe E, Ray CD, Dutta SK, Chakravarty B, Bordignon V, Duggavathi R and Chaudhury K: Dysregulated leukemia inhibitory factor and its receptor regulated signal transducers and activators of transcription 3 pathway:A possible cause for repeated implantation failure in women with dormant genital tuberculosis? Fertil Steril pii: S0015-0282 02184-6, 2016. [Epub ahead of print]

39. Moberg C, Bourlev V, Ilyasova N, Olovsson M. Endometrial expression of LIF and its receptor and peritoneal fluid levels of IL-1 $\alpha$ and IL- 6 in women with endometriosis are associated with the probability of pregnancy. Arch Gynecol Obstet 292:429-437, 2015. 